\title{
Need of Restructuring Teacher Education Programmes in India: An Essence for Globalization
}

\author{
Prakash Chandra Jena \\ School of Education, Lovely Professional University, Punjab, India \\ E-mail address: drpcjena@gmail.com
}

\begin{abstract}
For inculcating quality education the role of teacher is vital. In other words, quality of teaching largely depends on the quality of training received by the teachers. For this, designing curriculum and supportive resources occupies significant role. National Council of Teacher Education (NCTE 1998) identified ten competencies for making teachers professionally competent. These are contextual, conceptual, content, transitional competencies, competencies related to educational activities, developing teaching learning materials, evaluation, management, competencies related to working with parents and with community and other agencies. For fulfilling these competencies, curriculum of the teacher education program need to be reconstructed according to the changing aspects and needs of the society. But the task may face many challenges at the grass root level of the teacher education program in India. Present paper focus on how to redesign teacher education curriculum in India and identifying major difficulties in the light of teacher education programs.
\end{abstract}

Keywords: role of teacher; teaching; NCTE; teacher education programs

\section{INTRODUCTION}

Our society is changing fast and with the advancement of time, there has been explosion of expectations in every walk of life including education The role and responsibilities of the teacher are infinite and limitless since he is an instructor, a therapist, a guarantor of happiness, and an engineer of warm personal relationships among his students. Education is undergoing constant changes under the effects of internationalization and so is teacher education.

Internationalization and technological advancements are delivering and increasing access to the world and subsequently teacher education should reflect this global outlook. The internationalization of higher education can be linked to various changes in the international system. There have been changes in the labor market, which have resulted in calls for more knowledge and skilled workers, and workers with deeper understandings of languages, cultures and business methods all over the world. This phenomenon is reflected in teacher's education too.

Policy- makers and educators in each country have to think how to reform aims of teacher education for preparing their young teachers to more effectively cope with the challenges in the new era. In facing the fast changing environment, many policy- makers and educators get confused with uncertainties and ambiguities and lose their directions in the rapid globalization, 
which has driven numerous educational changes in the different parts of the world. There is an urgent need of a comprehensive framework for understanding the impacts of rapid developments and advancing implications for innovations in teacher education. How education can be transformed from a traditional site-bounded paradigm towards a new paradigm for borderless education? This is a challenge of the new millennium in the new century; graduates from education should not be limited to be technicians or experts in certain areas but also be intelligent leaders and citizens for development of the society in different areas. They have the potential to become contextualized multiple intelligent citizens to creatively and wisely lead the development of the whole society or the global village in facing up challenges in the new century. Borderless education will provide innovative ideas and possibilities for reforming education in different parts of the world to meet the challenges for the future.

Teachers should be trained in such a way that their potentials can be maximized to facilitate students' learning in an optimal way. Teaching is considered a process to initiate, facilitate, and sustain students' self- learning, self- exploration and self-actualization; therefore, teachers should play a role as a facilitator or mentor who supports students' learning. The focus of teaching is to arouse students' curiosity and motivation to think, act, and learn. Teaching is also to share with students the joy of the learning process and outcomes. To teachers themselves, teaching is also a life long learning process involving continuous discovery, experimenting, self actualization, reflection, and professional development. The aims of teacher education should be to develop teachers as leaders and citizens who will creatively contribute to the formation of a global society with multiple developments in technological, economical, social, political, cultural, and learning aspects. The rise of a global society, driven by technology and communication developments are shaping children ( the future citizens of the world) into 'global citizens', intelligent people with a broad range of skills and knowledge to apply to a competitive, information based society. The future of countries often lies within their ability to compete in a global market where industrial based economies are giving way to knowledge based industries, realizing the importance of knowledge, skills and the intellectual capacity to meet the challenges of accelerated change and uncertainty. Education is becoming a lifelong learning and training process, developing transferable skills and knowledge that can be applied to competitive markets where knowledge and information are being traded as a commodity. The Internationalization of education has become one of the key themes of educational policy and planning in the 1990s and the integration of worldwide capital and labor markets; educators are being forced to respond to a new set of challenges.

The universities providing a high quality education for the globalize world, despite its focus on internationalization and cross-cultural communication, are still based on an individualistic model of teaching. Through Globalization of education, which is being knowledge transfer from the Western countries into developing countries, is intended to improve the skills and capabilities of the people receiving it. David Orr (1999) argued that Western education has in fact replaced "indigenous forms of education throughout the world and focuses on preparing students exclusively for an urban existence." He also claimed that through this process, people are losing their vernacular knowledge, by which he meant "the knowledge that people have of their places', that is a loss of their cultural worth and he also believed that "our graduates of tomorrow will be trained, above all, to keep the wheels of the global economy turning". But the Western style of education is inadequate as it focuses largely on the creation of money and paying no attention to the preserving of cultures. Education should not become a means of westernizing the world. On the contrary, it should treat each unique culture and society with due respect, realizing that global education is not only learning 
about the West, but also studying different cultures of the world, using different approaches, ways of teaching and different media.

Through internationalization of teacher education supports and networks can be brought in to maximize the opportunities for teachers' developments in teaching and research and for their contribution to students' learning. Teachers can maximize the opportunities to enhance effectiveness of their teaching from local and global networking and exposure through internet, web-based teaching, video-conferencing, cross-cultural sharing, and different types of interactive and multi-media materials. Teachers are grouped and networked locally and globally to develop and sustain a new professional culture and multiply their teaching effects through mutual sharing and inspiring. They become world class and networked teachers through internationalization and localization.

\section{Global challenges in Indian teacher education:}

$>$ Curriculum design

$>$ Professional practice

$>$ Qualitative education in teacher education

$>$ Privatization in teacher education

$>$ IT or ICT facilities in the teacher training colleges

$>$ Duration of course

$>$ Admission process

$>$ Training schedule

$>$ Attitude of trainee teacher

$>$ Teacher educator

$>$ Curriculum framework of teacher education

$>$ Government recruitment procedure

\section{Threats in Teacher Education:}

$>$ Difficulty in bringing uniformity by overcoming the regional disparities

$>$ Scarcity in getting SLET / NET staff for teacher education colleges

$>$ Lack of teacher commitment to the profession

$>$ Matching the training skills with the skills needed to teach at different levels of education

$>$ Problem of rapid privatization and commercialization at teacher education

$>$ The problem of providing link between different levels of education

$>$ No proper upgradation of curriculum in pace with the growing changes

$>$ Poor management and utilization of institutional resources

$>$ Poor link between schools and colleges education

$>$ Rare opportunities to attend the standard and capacity building programme

\section{Some of the major thrust areas are given below}

$>$ Preparing teachers to integrate indigenous knowledge in the theory and practice of modern educational thoughts.

$>$ Empowering teachers to evolve culture specific pedagogy for the learners

$>$ Developing among teachers the skills of communications and language proficiency

$>$ Inculcating among teacher, love for the country and appreciation of various national concerns.

$>$ Orienting teachers in new curricular areas 
$>$ Developing among teachers an understanding of the impact of forces like liberalization, privatization, globalisation and information and communication technology

$>$ Capacity building in utilization of new findings of research community experience and institution based and field based experiments

$>$ Enabling teachers to appreciate and acquaint them with life skills

$>$ Developing among teachers awareness and sensitivity towards environment concern.

\section{CHALLENGES AHEAD OF A TEACHER EDUCATION}

\section{Professionalism}

The education standard will improve if all the teachers have global perspective, well prepared \& provided with ongoing professional development and appropriate support.

\section{Improvement in the quality of course content}

To revise the teacher-education curriculum in accordance with existing needs, to judge the suitability and effectiveness of some new teacher-training strategies etc which will provide greater scope for development of sound knowledge on different areas i.e. content knowledge, knowledge on teaching-learning methodologies and knowledge on pedagogy of teaching learning among the trainee-teachers in content areas, development of skills of trainee-teachers to be competent enough regarding how to transact the content materials to the students of the schools meaningfully. It gives stress on practical activities like internal assessment, project works, sessional works, internship in teaching, practice of micro-teaching skills, community works, practical works relating to work experiences innovative ways for conducting practical activities related to health and physical education, work experience, fieldwork with community etc.

The content materials of its programme are transacted to the trainee-teachers through many innovative teaching-learning strategies like problem solving, group discussion, panel discussion, seminar reading, brain storming, practical and project work, discovery method, competency based teaching, contextual transaction of the contents, demonstration-cumdiscussion, participatory / activity based group work, case studies, practical exercises, innovations, individual / group assignment, face to face contact, tutorial / library work, research approach etc.

\section{ICT Training}

Educating the learners to use the new technology. Most of the teacher educator does not have the knowledge of operating these electronic media, therefore it is essential to impart training to the teacher educator in the skills of developing. It is very useful for sharing of the best human and material resources .Teachers must use networking system and subsystems. Networking will be able to help cut costs ensure homogeneity in the standard of instructions and assure quality.

For Seminars and presentation students must make use of multimedia. Preparation of Lesson plans, Blue print and question bank, analysis \& interpretation of various Test papers should be based on ICT. The report submission of field based activities \& project work done by the students should be submitted in the CD. Forms\& Use of web based references may be allowed \& encouraged. 


\section{Infrastructural facilities}

Most of the students are sore the poor arrangements at the Institute. There is a need to provide all these facilities.

\section{Organization of effective student support services}

There is a need of developing good Institute with effective students support services.

\section{Prompt reply to the queries of the learners}

Maintenances of student profile and their records through computerize is must.

\section{Provision of educational administration}

A good educational administration can ensure the achievement of education goals in time. Educational administration can help to make available the services required to meet the demands not only of these who have easy accessibility but also the demands of those who are usually too poor or too remote geographically or socially

\section{Restructuring the Teacher Education Programme}

Teacher Education can be categorized into four categories - pre-primary, primary, secondary, higher. We may keep in view the requirements of each stage when we are structuring the teacher education programme. According to the approach paper prepared by NCERT four alternative models for the professionalization of secondary school teachers are; (a) One year of professional and education leading to B.Ed degree after Graduation (b) 4 - 5 years integrated professional courses after higher secondary leading to B.Ed./M.Ed. degrees (c) two years of professional education after graduation leading to M.Ed. degree, (d) Correspondence-cum-contact programme for graduate teachers in service leading to B.Ed degree.

The courses and programme may be structured so as to allow continuity and flexibility. The first course may lead to second course and so on. The candidates who have completed the certificate course in teacher education at one time may be allowed to join the degree course in education later on. Teacher education lacks both academic and professional rigor. B.Ed programme should be made of two years as one year duration is inadequate to develop skills and competence in the prospective teacher. Moreover like other professional courses there should be a provision of internship training and post internship training. Attractive packages should be provided for the prospective teacher during his/her post internship training.

\section{Selection of Candidates for Teacher Education}

It is generally believed that residue of all professional seekers enters into the teaching profession. Teaching is considered to be least attractive, prestigious occupation amongst the all. Therefore we should make a proper selection of prospective teachers. The candidates should be selected for admission on the basis of their academic qualifications, scores of written tests and interviews. The written tests should check their teaching aptitudes, knowledge of child psychology and reasoning power. It would generate confidence in teacher trainees that they are not inferior to the candidates who have been selected through entrance test for medical, engeering and other professional courses. Moreover competent candidates will be selected by adopting this procedure. 


\section{Incorporation of Information Technology in Teacher Education}

Today is the era of e-education, e-business and e-administration. The computer, T.V, Telephone, Mobile are the media of information. The world has become interdependent and is turning gradually into a global village. Now a days one has to think globally \& act locally. There is a necessity of integrating technology in teacher education. ICT is a tool for Communication and presentation, bringing teacher, students $\&$ teacher educators on a common bench which will results in effective exchange of views, presentation of ideas and feedback. Each teacher need to be proficient in the areas of technical competences required for chats, websites, data bases, audio \& video links, electronic conferences, e -mail etc. Learning to use computers $\&$ the internet is a relatively simple task, but mastering ICT use as an effective tool to improve teaching \& learning is considered a difficult one. Teachers need training in computer literacy \& how to use this in improving teaching and learning. Teacher Education Institutions must introduce Information and Communication Technology (ICT) as one full paper in the B.Ed programme. The techno - pedagogical skills need to be cultivated among the trainees, gradually so that both students and teachers are able to make use of the same in their teaching learning styles. The students should experience innovative technology supported learning environments in their teacher education programmes. The institutions must full fill the requirements of the availability of selected ICT. Moreover well qualified and experienced technical staff should be appointed to take care of the ICT labs.

\section{Reorganization of Curriculum}

Teacher education in the new millennium must have quality we should enhance its various functions and activities including quality of courses, quality of teaching and the quality of curriculum. The curriculum should not only be relevant to the needs of the society, it should also make pupils employable and self entrepreneurs. Therefore, curriculum needs to be relevant to socio-economic needs and up to date in contents. The curriculum of the teacher trainees should be made inter disciplinary to facilitate the acquisition of skills, competence and abilities. While constructing the curriculum for teacher trainees due care should be taken so that it will develop competences among the teachers in respect of classroom management \& administration, in relation to motivation and values. The competency can be developed by introducing various academic \& co-curricular activities such as seminars, workshops, discussions, brainstorming, symposiums, role playing, etc. Competency based teacher education curriculum should make teachers discharge their duties efficiently. It should also enhance the teaching skills of the teachers.

While constructing the curriculum proper attention has to be paid to Art, Health \& Physical Education, Science \& Technology. Art education will develop artistic attitude and aesthetic sensibility. Yogic education can be integrated with health \& physical education for improving both physical health as well as mental health. Science \& Technology is the need of the present era. Teacher education programmes have also to translate into reality the message of Delors Commission through its curricula at all levels for strengthening the four pillars of learning viz., Learning to know, Learning to do, Learning to live together and Learning to be. Prospective teachers will need to be empowered by teacher education for developing these skills among themselves and their students. Integrations of these four guiding principles in teacher education curricula is essential for serving the concern of the society. 


\section{Improvement in Evaluation System}

The evaluation system for the assessment of teachers under training has many weak features. We are not having a uniform system of evaluation for the whole country moreover the present evaluation system in teacher lays over emphasis on development of scholastic aspects at the cost of non-scholastic aspects. Moreover it lacks reliability; objectivity and validity. Variation exists in the award of divisions \& distinctions. Some of the agencies like NCERT \& CASE (Baroda) have developed evaluation Performa. There is a teacher competence appraisal guide developed in the USA for the assessment of practice teaching. These can be used while assessing the performance of teacher trainees. Teacher education programme has two parts - Theory \& Practical work including the student teaching. An equal weight age should be given to theory \& practical aspect. We should also introduce an evaluation system which will have internal \& external assessment for both the theory paper as well as practical paper. Moreover the marks awarded should be shown for both the papers separately. Grading system should be adopted in which separate grades for each item should be assigned. The candidate should also be permitted to make an improvement in grade by taking subsequent examination. Teacher evaluation system must have multiple perspectives. Multiple criteria should be set up. Multiple tools such as paper pencil tests, observation techniques, self reporting devices \& peer appraisal can be used. The process of evaluation should be continuous, comprehensive \& participative. This will provide timely feedback to the student teacher for improving their performance. Thus, providing an opportunity to them for self evaluation and self improvement.

\section{In-Service Education of Teachers}

The in-service programme of teacher education will keep the teachers up-to-date in respect of their knowledge of their subjects, specialization subjects \& the professional skills of teaching. This will help the teachers to update their knowledge \& skills according to scientific $\&$ technological advancements. Hence they will be able to meet the new challenges effectively. The in-service training programme includes periodic refresher courses, professional enrichment courses, orientation in various emerging areas like value education, special education, communication technology, human rights education, environment education etc. Active participation of teachers in workshops, conferences \& seminars organized at National $\&$ International level should be encouraged.

\section{Standard of Teacher Education Institutes be raised}

It is well said that no system of education, no syllabus, no methodology and no text book can rise above the level of the teacher and level of the teacher depends upon the standard of teacher education. Due to mushrooming growth of sub-standard teacher education institution, the standards of teacher education have been lowered. The owners of the self financing institutions invest huge amount of money and other infrastructural facilities. They are eager to recover the investment as early as possible even at the cost of training effectiveness. Some of the institutions don't have qualified staff to teach. Many teacher education institutions do not follow the guidelines regarding the curriculum of teacher education programme for theory and practical. Realizing the need for regulation to insure the quality a number of regulatory bodies like NCTE, UGC, NAAC, etc. are set up. These bodies establish quality affiliation norms and supervisory norms for the teacher education institutions. 


\section{CONCLUSION}

Teachers are the hope of a nation. There are lots of challenges in teacher education. The teachers have to acquire professional competencies, commitment and empowerment to perform multiple tasks inside and outside the classroom. The international commission on education for $21^{\text {st }}$ century emphasized that; "Rethinking of teacher education is necessary, in order to bring out the future teachers precisely those human and intellectual qualities that will facilitate a fresh approach to teaching". Thus teacher education should be designed to train teacher trainees to meet the challenges of $21^{\text {st }}$ century so that every teacher will enjoy teaching.

\section{References}

[1] APJ Abdul Kalam (2005). The President of India. Our National Mission and Challenges, University News 43(09) (2005) 15.

[2] Arora G. (2002). Globalization, Federalism and Decentralization Implications for India. Book Weel.

[3] Joshi R., Challenges to Teacher Education in $21^{\text {st }}$ Century, University News 43(18) (2005).

[4] Mumthas N. S. (2005). Professionalism among teacher educators, EDUTRACKS, Neelkamal Publication Pvt. Ltd., Hyderabad, A.P., India.

[5] Prasanand Prasad, Towards professionalization in Education. University News 43(18) (2005).

[6] Taj H. (2004). Information Communication Technology and Teacher Education, EDUTRACKS, Neelkamal Publication Pvt. Ltd. Hyderabad, A.P., India. 